\title{
NILAI PENDIDIKAN SOSIAL DALAM TARI MOYO (TARI ELANG) PADA MASYARAKAT NIAS DI KOTA MEDAN
}

\author{
ARVIKA TARI \\ Prodi Pendidikan Tari
}

\begin{abstract}
This study aims to determine how the value of social education contained in Moyo Dance (Dance Eagle) on Nias people in the city of Medan. The theory used in this research is the theory of Hermin Kusumawati form of presentation, educational value of social theories of Edward Purba and Yusnadi. The method used is descriptive qualitative. The population in this study is the Nias community berurbanisasi to Medan. While the sample in this study is one of traditional artists from the studio Furai Nias, one singer, and 4 (four) dancers Moyo Dance (Dance Eagle). To complete the data in this study, researchers conducted a field observation, documentation in the form of videos and photographs and conduct interviews. The results based on the data collected can be seen that Moyo Dance (Dance Eagle) is a welcome dance performed by girls Nias to greet guests in the wedding. Moyo Dance (Dance Eagle), which developed in the city of Medan has entertainment functions of a commercial nature or as dance performances, because this dance is often performed for weddings. Shape Dance Moyo (Dance Eagle) in the city of Medan there are 10 varieties of motion is the motion the wing (mamologo afi), motion dealing (fatahö), motion disputing (Faonda), circles (sieligö), sight (fatahö) back, disputing ( Faonda), communicating (fahuhuo), pick (famaondragö), circles (sieligö), and then back (mangawei). Social educational value contained in Moyo Dance (Dance Eagle) is a sense of togetherness that is contained in the range of motion mamologo afi, faonda, and sieligö. A sense of ownership contained in the motion famaondragö. The sense of responsibility is seen in motion sieligödan famaondragö. Compactness seen from mamologo afi. And a sense of attachment and affection seen in motion fahuhu.
\end{abstract}

Keywords: Moyo Dance (Dance Eagle), Social Education Value 
PENDAHULUAN

Suku Nias adalah masyarakat yang hidup dengan adat kebudayaan yang memiliki hukum-hukum adat yang masih berlaku. Dalam pergaulan masyarakat Nias itu sendiri mereka banyak membuat suatu komunitas atau organisasi sosial agar tali persaudaraan tetap terjalin. Dalam kegiatan di lembaga atau komunitas tersebut termasuklah di dalamnya kegiatan-kegiatan kesenian contohnya seni rupa, seni musik dan seni tari. Contoh salah satu seni tari yang mereka miliki adalah Tari Moyo (Tari Elang).

Tari ini dulunya ditarikan oleh dayang-dayang kerajaan. Tarian ini ditampilkan pada saat sang raja atau ratu hendak pergi keluar kerajaan. Tari Moyo (Tari Elang) ini ditampilkan dengan gerak-gerak yang sederhana dan dengan musik yang sederhana pula tetapi seiring perkembangan zaman, Tari Moyo (Tari Elang) ini juga mengalami perkembangan dari segi musik serta bentuk tarinya. Keberadaan tarian ini di kota Medan sampai sekarang masih sering ditampilkan, baik di dalam acara pernikahan masyarakat Nias maupun acara pemerintahan dan acara budaya yang mengikutsertakan adat Nias di dalamnya.

Tari Moyo (Tari Elang) ini juga dulunya ditarikan sebagai upacara penyambutan saat panglima telah kembali dari berperang. Tarian ini melambangkan sukacita seorang ibu atas kepulangan anaknya dari peperangan. Tari Moyo (Tari Elang) ini merupakan tarian yang sangat istimewa, oleh karena itu tarian ini dulunya ditampilkan dalam acara-acara tertentu, seperti penyambutan saat para panglima kembali dari berperang, dalam acara-acara kerajaan untuk menghibur para raja dan ratu serta menyambut para tamu-tamu raja lalu ditampilkan lah tarian ini.

Tari Moyo (Tari Elang) ini juga memiliki arti kebersamaan, yang tercermin dari bentuk penyajian tarinya. Tarian ini memperlihatkan keserempakan gerak antara penari yang satu dengan penari yang lainnya. Nilai-nilai sosial juga banyak terkandung dari setiap gerakan Tari Moyo (Tari Elang) ini, yang terlihat dari pola maupun gerak-gerak interaksi antar penari.

Maka berdasarkan uraian latar belakang di atas, penulis merasa tertarik untuk mengkaji nilai-nilai pendidikan sosial yang terkandung di dalam tari ini untuk ditulis dalam bentuk skripsi. Maka dari itu penulis ingin mengangkat tarian tersebut menjadi topik penelitian dengan judul "Nilai Pendidikan Sosial Dalam Tari Moyo (Tari Elang) Pada Masyarakat Nias di Kota Medan." 


\section{Tujuan Penelitian}

1. Untuk mendeskripsikan bagaimana bentuk Tari Moyo (Tari Elang) pada masyarakat Nias di Kota Medan.

2. Untuk mendeskripsikan bagaimana nilai pendidikan sosial pada Tari Moyo (Tari Elang) dalam masyarakat Nias di Kota Medan.

\section{Landasan Teori}

Untuk membahas tentang Bentuk Penyajian dan Nilai Pendidikan Sosial, penulis menggunakan beberapa teori yaitu teori bentuk penyajian oleh Hermin Kusumawati yaitu bentuk penyajiannya tari ditopang oleh berbagai elemen yaitu: gerak tari, pola lantai, iringan, tata rias dan busana, properti serta tempat pementasan. Serta teori dari Edward Purba Dan Yusnadi yang berdasarkan landasan sosiologi yang akan menumbuhkan rasa kebersamaan, rasa ikut memiliki, rasa tanggung jawab, kekompakan serta rasa keterikatan dan rasa sayang kepada sesama akan diidentifikasikan berdasarkan bentuk penyajian Tari Moyo (Tari Elang) tersebut.

\section{Lokasi dan Waktu Penelitian}

Sesuai dengan judul penelitian yaitu Nilai Pendidikan Sosial Dalam Tari Moyo (Tari Elang) Pada Masyarakat Nias di Kota Medan, maka penelitian ini akan mengambil lokasi di Medan, tepatnya di Jalan M. Basir Gang Damak Kelurahan
Rengas Pulau Kecamatan Medan Labuhan Kota Medan.

\section{Populasi dan Sampel}

\section{Populasi}

Populasi dalam penelitian ini adalah Masyarakat Nias yang ada di Jalan M. Basir Gang Damak pada Kelurahan Rengas Pulau Kecamatan Medan Labuhan Kota Medan.

\section{Sampel}

Sampel dalam penelitian adalah satu orang seniman tradisional Nias dari sanggar Furai yang ada di Jalan M. Basir Gang Damak pada Kelurahan Rengas Pulau Kecamatan Medan Labuhan Kota Medan, satu orang penyanyi, dan 4 (empat) orang penari Tari Moyo (Tari Elang).

\section{Teknik Pengumpulan Data}

Teknik pengumpulan data yang dilakukan adalah sebagai berikut:

1. Observasi Lapangan

2. Wawancara

3. Dokumentasi

4. Kajian Pustaka

\section{Teknik Analisis Data}

Dalam penelitian ini data yang digunakan adalah teknik analisis data kulitatifdimanaproses mencari dan menyusun secara sistematis data-data yang diperoleh dari hasil wawancara, catatan lapangan, dan dokumentasi. 
ISI

\section{A. Masyarakat Nias di Kota Medan}

Sumatera Utara (Kota Medan)

menjadi tempat dimana orang Nias terus melakukan proses perpindahan atau urbanisasi untuk melanjutkan kehidupan. Suku Nias yang awalnya hanyalah kelompok kecil kini terbentuk menjadi sebuah masyarakat suku Nias yang hidup saling berdampingan dengan suku lain. Dalam pergaulan masyarakat Nias itu sendiri mereka banyak membuat suatu komunitas atau organisasi sosial agar tali persaudaraan tetap terjalin termasuk di daerah Kecamatan Medan Marelan yang memiliki suatu daerah yang mayoritas masyarakatnya adalah masyarakat Nias terutama yang berasal dari Nias Selatan.

Di lingkungan inilah bapak Famaigi Z. Manao mulai membentuk sanggar Nias untuk melestarikan budaya Nias tersebut di Kota Medan. Menurut wawancara dengan narasumber yaitu selaku pimpinan sanggar Furai ini sendiri yaitu Bapak Famaigi Z. Manao, sanggar Furai merupakan sanggar Nias yang digunakan masyarakat Nias untuk latihan dalam bentuk kesenian musik dan juga tari. Sanggar ini berpusat di Kelurahan Titi Kuning Kecamatan Medan Johor. Sanggar Furai ini memiliki 1 cabang yaitu di Kelurahan Rengas Pulau Kecamatan Medan Marelan. Sanggar ini dahulunya disebut dengan Perkumpulan Masyarakat Nias (PERMANI). Pendiri sanggar ini yaitu Famaigi Z. Manao yang didirikan pada tahun 1995.

Di dalam sanggar Furai ini banyak sekali dipelajari tarian-tarian yang berasal dari masyarakat Nias. Beberapa tarian yang sering ditampilkan di dalam sanggar ini yaitu Lompat Batu (Fahombo), Tari Perang (Faluaya), Tari Fogaele dan Tari Elang (Tari Moyo).

\section{Suku Nias di Kota Medan}

Masyarakat Nias yang ada di Kota Medan terutama yang ada di Jalan M.Basir Gang Damak banyak yang berasal dari Nias Selatan. Mereka masih sering mengadakan upacara adat dimana banyak acara kesenian didalamnya terutama acara pernikahan. Karena banyaknya kebutuhan adat yang terkandung di dalam masyarakat Nias, tidak dipungkiri bahwasanya masyarakat Nias memiliki berbagai macam kesenian diantaranya seni tari, seni musik, dan seni rupa atau seni pahat.

\section{Karakteristik Masyarakat Nias}

Kebudayaan masyarakat Nias meliputi banyak sekali kegiatan kesenian diantaranya yaitu Lompat Batu, Tari Perang, Tari Maena, Tari Moyo, Tari Fogaele serta sapaan "Ya'ahowu”. Semua jenis kesenian tersebut masih sering ditampilkan di dalam kebudayaan masyarakat Nias dengan tujuan agar segala 
peninggalan kebudayaan masyarakat Nias masih bisa dinikmati oleh setiap kalangan masyarakat Nias secara terus-menerus termasuk juga masyarakat Nias di Kota Medan ini.

Dalam adat budaya Nias dikenal dengan sapaan salam "Ya'ahowu" yang menjadi simbol kekerabatan dari masyarakat Nias itu sendiri. Masyarakat Nias di Kota Medan atau yang berkembang di Kelurahan Rengas Pulau ini sendiri juga masih tetap mengucapkan salam "Ya'ahowu" kepada masyarakat yang lain ketika saling menyapa satu sama lain.

\section{B. Tari Moyo (Tari Elang)}

\section{Isi Cerita}

Tari Moyo (Tari Elang) merupakan salah satu tari yang dimiliki oleh masyarakat Nias yang dibawakan oleh wanita-wanita dari suku Nias. Pada zaman dahulu, Tari Moyo (Tari Elang) ini ditampilkan di dalam acara-acara kerajaan sebagai tari penyambutan yang dulunya ditarikan oleh dayang-dayang kerajaan, yang ditampilkan pada saat sang raja atau ratu hendak pergi keluar kerajaan. Tari ini juga sering ditampilkan sebagai tari penyambutan, untuk menyambut tamutamu kerajaan maupun menghibur para raja dan ratu yang telah kembali ke kerajaan.
Tari Moyo (Tari Elang) hingga kini masih sering ditampilkan yaitu didalam pesta adat perkawinan masyarakat Nias maupun acara adat lainnya. Hanya saja bentuk Tari Moyo (Tari Elang) yang ada di Kota Medan, sedikit berbeda karena bergantung kepada bentuk acara pelaksanaanya, serta permintaan dari pihak yang mengundang para seniman Nias untuk mengisi acara di Kota Medan baik di acara pernikahan maupun acara hiburan pemerintahan.

Tari Moyo (Tari Elang) yang ada di Kota Medan, biasanya dibawakan oleh para gadis-gadis yang berasal dari Nias. Konsep Tari Moyo (Tari Elang) adalah tari hiburan seperti halnya pada sanggar Furai ini sendiri. Biasanya jika Tari Moyo (Tari Elang) ini ditampilkan di acara pesta adat perkawinan, tarian ini selalu ditampilkan beriringan dengan urutan yang pertama yaitu lompat batu kemudian tari perang lalu dilanjutkan dengan Tari Moyo (Tari Elang) lalu yang terakhir adalah Tari Fogaele lalu setelah itu barulah para penari membawakan persembahan sirih kepada pengantin dan para tamu yang datang.

$$
\text { Walaupun terdapat banyak }
$$
perubahan serta perbedaan antara bentuk Tari Moyo (Tari Elang) yang terdapat di Nias dengan yang ada di Medan tetapi tidak merubah nilai-nilai pendidikan sosial 
didalam Tari Moyo (Tari Elang) tersebut. Pada dasarnya, para masyarakat Nias merasa bangga bisa memperkenalkan budayanya kepada masyarakat yang ada di Kota Medan salah satunya lewat Tari Moyo (Tari Elang) ini agar masyarakat di Kota Medan tahu bagaimana sebenarnya masyarakat Nias itu sendiri hidup bersama dengan sesamanya, serta masyarakat Nias yang memiliki banyak nilai-nilai pendidikan sosial diantaranya nilai kebersamaan bahkan rasa sayang terhadap semua orang.

\section{Bentuk Penyajian Tari Moyo (Tari Elang)}

Sesuai dengan teori Hermin yang menyatakan bahwa dalam bentuk penyajiannya tari ditopang oleh berbagai elemen yaitu: gerak tari, pola lantai, iringan, tata rias dan busana, properti serta tempat pementasan, dengan demikian penulis akan menguraikan bagaimana bentuk penyajian Tari Moyo (Tari Elang) sesuai dengan bagaimana ragam geraknya yaitu terdapat 10 ragam didalam Tari Moyo (Tari Elang) ini yaitu gerak kepak sayap (mamologo afi), gerak berhadapan (fatahö), gerak berselisih (Faonda), lingkaran (sieligö), berhadapan (fatahö) kembali, berselisih (Faonda), berkomunikasi (fahuhuo), menjemput (famaondragö), lingkaran (sieligö), lalu kembali (mangawei, bagaimana pola lantai, iringan musik maupun syair yang terdapat didalam Tari Moyo (Tari Elang) serta tata rias dan busana, properti apa yang biasanya digunakan dan dimana biasanya Tari Moyo (Tari Elang) ini ditampilkan.

\section{Nilai Pendidikan Sosial Dalam} Tari Moyo (Tari Elang)

\section{a. Menumbuhkanrasa}

\section{kebersamaan}

Rasa kebersamaan ini terlihat dari gerakan Tari Moyo (Tari Elang) saat pertama kali masuk yaitu gerak mengepakkan sayap secara bersamaan yaitu terlihat seperti elang yang terbang secara bersama-sama dan berkelompok menandakan mereka memiliki rasa kebersamaan dalam menjalani aktifitas kehidupan.

Rasa kebersamaan itu juga terlihat di dalam gerakan saat berselisih dan membentuk lingkaran. Gerakan ini terlihat seperti elang yang sedang bercengkerama dengan elang yang lain. Lalu penari tersebut membentuk posisi lingkaran yang menandakan mereka adalah satu kelompok yang punya tujuan bersama yaitu kelompok masyarakat Nias walaupun mereka berasal dari keluarga yang berbeda-beda tetapi mereka bersaudara dan tetap menjalin hubungan kerja sama yang baik.

\section{b. Rasa Ikut Memiliki}


Rasa ikut memiliki ini terlihat dari gerakan Tari Moyo (Tari Elang) pada bagian menjemput atau menghampiri penari yang lain. Gerakan ini mencerminkan seekor elang yang menghampiri elang yang lain yang sedang kesusahan serta memberikan pertolongan kepada elang yang lain serta ikut merasakan apa yang elang itu rasakan. Gerakan ini juga mencerminkan kehidupan gadis Nias atau masyarakat Nias yang memiliki sifat rasa kepedulian yang tinggi antar sesama, serta ikut meringankan beban diantara sesamanya.

\section{c. Rasa Tanggung Jawab}

Nilai tanggung jawab didalam Tari Moyo (Tari Elang) yaitu terletak juga pada gerakan yang tergambar seperti seekor elang yang menghampiri seekor elang yang lain. Gerak ini menceritakan tentang elang yang peduli serta rela berkorban terhadap sesamanya. Lalu setelah itu mereka mendekat lalu berputar terlihat seperti elang yang saling mengayomi, serta bertanggung jawab atas keselamatan sesamanya lalu melanjutkan mencari makan secara bersama-sama untuk keluarga mereka.

\section{d. Kekompakan}

Nilai kekompakan ini terlihat dari gerakan Tari Moyo (Tari Elang) pada saat penari pertama kali memasuki pentas. Terlihat bahwasanya para penari menggerakkan tangannya atau mengepakkan sayapnya secara serempak seperti elang yang sedang terbang di angkasa.

Nilai ini juga merupakan cerminan dari masyarakat Nias yang selalu mengutamakan kekompakan dalam segala hal pada aspek kehidupan bermasyarakat.

\section{e. Rasa Keterikatan dan Rasa Sayang \\ Didalam Tari Moyo (Tari Elang)} juga mengandung nilai keterikatan dan rasa sayang yang tergambar dari gerakan menghampiri serta berinteraksi dengan elang atau penari yang lain. Dari gerakan tersebut dapat terlihat bahwasanya para elang atau penari mempunyai rasa keterikatan dengan elang yang lain yang membutuhkan bantuan. Mereka pun saling menghampiri, saling berinteraksi dan saling menyayangi serta ikut merasakan apa yang elang lain rasakan.

\section{PENUTUP}

\section{Kesimpulan}

Dari hasil penelitian dan pembahasan, maka dapat diambil beberapa kesimpulan sebagai berikut:

1. Tari Moyo (Tari Elang) berfungsi sebagai tari hiburan. Pada masyarakat Nias sendiri tarian ini di zaman 
sekarang masih sering ditampilkan disetiap acara adat Nias meliputi acara pernikahan, pesta rakyat bahkan pesta adat yang lainnya. Tari ini ditampilkan sebagai tari hiburan dan bisa juga dijadikan sebagai tari penyambutan.

2. Masyarakat Nias banyak yang berurbanisasi ke kota Medan karena alasan melanjutkan pekerjaan, melanjutkan sekolah atau hanya sekedar mengadu nasib. Dari situlah kebudayaan Nias dikembangkan lewat pembentukan organisasi Nias atau sanggar atau perkumpulan masyarakat Nias lainnya yang dibentuk dari masyarakat Nias itu sendiri. Melewati itu pula mereka memperkenalkan budaya dari masyarakat Nias seperti seni rupa, seni musik dan seni tari termasuk salah satunya adalah Tari Moyo (Tari Elang) ini.

3. Bentuk Tari Moyo (Tari Elang) yang ada di Kota Medan terdapat 10 ragam gerak yaitu gerak kepak sayap (mamologo afi), gerak berhadapan (fatahö), gerak berselisih (Faonda), lingkaran (sieligö), berhadapan (fatahö) kembali, berselisih (Faonda), berkomunikasi (fahuhuo), menjemput (famaondragö), lingkaran (sieligö), lalu kembali (mangawei). Nilai pendidikan sosial yang terdapat dalam Tari Moyo (Tari Elang) yaitu rasa kebersamaan yang terdapat pada ragam gerak mamologo afi, faonda, dan sieligö. Rasa ikut memiliki terdapat dalam gerak famaondragö. Rasa tanggung jawab terlihat dalam gerak sieligö dan famaondragö. Kekompakan dilihat dari mamologo afi.

\section{DAFTAR PUSTAKA}


Adisusilo, Sutarjo. 2014. Pembelajaran Nilai-Nilai Karakter. Jakarta:Rajagrafindo Persada. Agustina, Inna. 2015. Nilai Gotong Royong Dalam Tari Top Pade Di Lhokseumawe Aceh Utara. Skripsi. Medan: Universitas Negeri Medan.

AR, Muchson dan Samsuri. 2013. Dasardasar pendidikan moral. Yogyakarta: Ombak.

Bangun, Christinawati. 2016. Bentuk Penyajian Dan Kontribusi Lagu Foe're Sebagai Pengiring Tari Moyo Di Sanggar Tari Baluseda Desa Bawomataluo Kecamatan Fanayama Kabupaten Nias Selatan. Skripsi. Medan: Universitas Negeri Medan.

Hadi, Y. Sumandiyo. 2012. Koreografi, Bentuk, Teknik, Isi. Yogyakarta: Cipta Media.

Jazuli, M. 2008. Paradigma Kontekstual Pendidikan Seni. Semarang: Unesa University Press.

Langer, Suzane K. 1988. Problema Seni. Terjemahan F.X. Widaryanto. 2006. Bandung: STSI Press.

Hermin, Kusumawati. 1980. Makna Tari dalam Upacara di Indonesia. Jakarta: Pidato.

Melisa, Laurensia Dora. 2015. "Studi Komparatif tari Faluaya Di Nias Selatan Dengan Tari Faluaya Di Medan”. Skripsi. Medan: Universitas Negeri Medan.

Purba, Edward dan Yusnadi. 2013.

Filsafat Pendidikan. Medan:

Unimed Press.

Royce, Anya Peterson. 1980. Antrhropology of Dance. Terjemahan F.X Widaryanto. 2007. Bandung: STSI Press.

Sagala, Syaiful. 2013. Etika dan Moralitas Pendidikan. Jakarta: Kencana.

Sari, Nur Utari Septiana N. R. 2013.Makna Gerak tari Faluaya (Tari Perang) Pada Masyarakat Nias Selatan Di Kota Medan. Skripsi. Medan: $\quad$ Universitas Negeri Medan.
Sembiring, Dermawan dkk.2015.Ilmu Sosial Budaya Dasar. Medan: Unimed Press.

Silaen, Marlina Uli. 2015. Pergeseran Fungsi Musik Gondra Pada Tari Moyo(Tari Elang)Masyarakat Nias Di Sanggar Tari Fanayama Simalingkar Medan. Skripsi. Medan: Universitas Negeri Medan.

Tafanaő, Agusman. 2012. Analisis Musik Vokal Pada Pertunjukan Maena Dalam Pesta Adat Falöwa (Perkawinan) Masyarakat Nias Di Kota Medan. Skripsi. Medan:Universitas SumateraUtara. 